Recibido: 27/03/2016 --- Aceptado: 05/09/2016 --- Publicado: 15/03/2017

\title{
LA PRIMERA APROXIMACIÓN DE HOLLYWOOD A LA GUERRA CIVIL ESPAÑOLA: THE LAST TRAIN FROM MADRID (1937)
}

Carmen Guiralt Gomar1: Universidad de Valencia. España.

carmenguiralt@yahoo.es

\section{RESUMEN}

La Guerra Civil española fue un tema prohibido de forma tácita en el Hollywood regulado por la autocensura de la Oficina Hays y la PCA. Como consecuencia, las productoras cinematográficas norteamericanas sólo realizaron tres films sobre la contienda mientras se desarrolló (1936-1939). Este artículo analiza el contenido histórico y discurso ideológico de The Last Train From Madrid (James Hogan, 1937), la primera aproximación de Hollywood a la guerra de España. Se trata de un film menor, apenas estudiado, que sigue sin estar editado comercialmente. Sin embargo, posee gran relevancia en lo que atañe a la visión inaugural que se ofreció al público estadounidense sobre la beligerancia española en una película de ficción. Tal punto de vista fue el resultado de las presiones de la autocensura, que se concretaron en una deliberada imparcialidad, visión distante y apolítica. Sus consecuencias fílmicas fueron la absoluta ambigüedad y la confusión. Así pues, el largometraje es claro reflejo de las posturas oficiales de neutralidad y no injerencia que compartían tanto la autocensura industrial hollywoodiense como el gobierno de los Estados Unidos y se instaura como vaticinio de lo que ocurrió en la historia: la no intervención de las potencias democráticas occidentales en el conflicto español.

\section{PALABRAS CLAVE}

The Last Train From Madrid - Guerra Civil española - Hollywood - autocensura cinematográfica - Oficina Hays - PCA - discurso político

\section{FIRST APPROACH OF HOLLYWOOD TO THE SPANISH CIVIL WAR: THE LAST TRAIN FROM MADRID (1937)}

\begin{abstract}
The Spanish Civil War was a tacitly forbidden topic in Hollywood controlled by selfcensorship of the Hays Office and PCA. Therefore, American film companies only produced three films about that war while it was taking place (1936-1939). This article analyses the historical content and the ideological discourse of The Last Train
\end{abstract}

\footnotetext{
1 Carmen Guiralt Gomar: Doctora en Historia del Arte por la Universidad de Valencia, Licenciada en Historia del Arte por la misma universidad y Máster en Historia y Estética de la Cinematografía por la Universidad de Valladolid. Sus líneas de investigación, publicadas en revistas científicas y expuestas en distintos congresos internacionales, se centran en la historia y la estética del cine clásico norteamericano.

carmenguiralt@yahoo.es
} 
from Madrid (James Hogan, 1937), the first approach of Hollywood to the war of Spain. This is a minor film, which has been barely studied by film analysts and is still commercially unavailable. Nevertheless, it is so relevant since it was the first view offered to the American public on Spanish belligerency in a fiction film. Such a point of view was the result of the restraint exercised by self-censorship, which took place by way of deliberate impartiality and a distant and apolitical stance. Its filmic effects were absolute ambiguity and confusion. As a result, this feature film is a clear reflection of the official attitudes of neutrality and non-interference shared by both Hollywood's self-censorship system and the United States Government, and it established itself as a prediction of what happened in history: non-intervention of democratic Western powers in the Spanish conflict.

\section{KEY WORDS}

The Last Train From Madrid (James Hogan, 1937) - Spanish Civil War -Hollywood film self-censorship - Hays Office - PCA - political discourse

\section{A PRIMEIRA APROXIMAÇÃO DE HOLLYWOOD À GUERRA CIVIL ESPANHOLA: THE LAST TRAIN FROM MADRID (1937)}

\section{RESUMO}

A Guerra Civil Espanhola foi um tema proibido de forma tácita em Hollywood regulada pela autocensura da Oficina Hays y La PCA. Como conseqüência, as produtoras cinematográficas norte americanas somente realizaram três filmes sobre a contenda enquanto esta perdurou (1936-1939). Este artigo analisa o conteúdo histórico e ideológico do The Last Train From Madrid (James Hogan, 1937), a primeira aproximação de Hollywood à guerra da Espanha. Trata-se de um filme menor, apenas estudado, que segue sem estar editado comercialmente. Mesmo assim possui grande relevância ao que se refere à visão inaugural que se ofereceu ao público estadunidense sobre a beligerância espanhola em um filme de ficção. Tal ponto de vista foi resultado das pressões da autocensura, que se concretizaram em uma deliberada imparcialidade, visão distante e apolítica. Suas conseqüências fílmicas foram absoluta ambigüidade e confusão. Assim, o filme é claro reflexo das posturas oficiais de neutralidade e não ingerência que compartiam tanto a autocensura industrial hollywoodiana como o governo dos Estados Unidos e se instaura como vaticínio do que ocorreu na historia: a não intervenção das potências democráticas ocidentais no conflito espanhol.

\section{PALAVRAS CHAVE}

The Last Train From Madrid - Guerra Civil Espanhola - Hollywood - Autocensura cinematográfica - Oficina Hays - PCA - Discurso Político 


\section{Cómo citar el artículo}

Guiralt Gomar, C. (2017) La primera aproximación de Hollywood a la Guerra Civil Española: the last train from Madrid (1937) [First approach of Hollywood to the Spanish Civil War: the last train from Madrid (1937)] Vivat Academia. Revista de Comunicación, 138, 16-36. doi: https://doi.org/10.15178/va.2017.138.16-36. Recuperado de http:/ / vivatacademia.net/index.php/vivat/article/view/990

\section{INTRODUCCIÓN}

Aunque Hollywood ha llegado a consumar alrededor de cincuenta films vinculados con la Guerra Civil española (Porta, 2008)², durante el tiempo que se disputó el conflicto (1936-1939) tan solo realizó tres largometrajes de ficción relativos al mismo: The Last Train From Madrid (James Hogan, 1937), producido por Paramount Pictures, Love Under Fire (George Marshall, 1937), de Twentieth Century-Fox, y Blockade (William Dieterle, 1938), un film independiente de Walter Wanger con distribución de United Artists.

Tal escasa atención a una guerra que estaba teniendo una enorme repercusión internacional no se debió desde luego a razones de simple "olvido". La Guerra Civil española fue un tema prohibido de forma tácita en el Hollywood regido por la Motion Picture Producers and Distributors of America (MPPDA), organización instaurada, en 1922, por los propios estudios para censurar los films y controlar la moralidad del cine norteamericano. Tanto dicho organismo, dirigido desde Nueva York por Will Hays - al que debió su designación popular de Oficina Hays - , como su delegación subsidiaria en Hollywood, la Production Code Administration (PCA), administrada, desde su creación en 1934, con mano de hierro por Joseph I. Breen, estaban auspiciados y controlados por ultraderechistas católicos que de inmediato se posicionaron contra el gobierno legítimo de la República española y a favor de las tropas sublevadas de Franco e hicieron todo lo posible para que la guerra de España no se representase en la pantalla (Black, 1998, p. 315; Coma, 2002, pp. 27, 29, 89; Doherty, 2013, p. 143).

Aunque conforme a los preceptos del Motion Picture Production Code (1930), conocido como Código Hays, los censores no podían impedir la realización de films sobre la Guerra Civil española (Doherty, 2013, p. 143) (el documento regulaba principalmente aspectos de índole sexual), lograron presionar a los estudios para que la evitasen basándose de manera prioritaria en tres argumentos. En primer lugar, apelaron a la cláusula del Código que señalaba que todas las naciones serían representadas sin posibilidad de ofensa (Coma, 2002, pp. 28-29, 89). En segundo, subrayaron la política oficial de neutralidad del gobierno estadounidense (Coma, 2002, pp. 29, 89). En tercero, y más importante, hicieron hincapié en las graves pérdidas económicas que ello supondría, dado que tales largometrajes, que Breen, ultraderechista, católico y pro franquista, presuponía leales a la República y a la democracia, no podrían distribuirse en multitud de países, como Alemania, Italia y

\footnotetext{
2 Para mayor información a este respecto, véase el listado de films incluido en Coma, 2002, pp. 207-220.
} 
gran parte de Latinoamérica (Coma, 2002, p. 30; Porta, 2008; Doherty, 2013, p. 138)33. En consecuencia, las majors hollywoodienses acataron la "prohibición" y no llevaron a cabo films sobre la guerra de España, salvo los tres únicos mencionados.

The Last Train From Madrid y Love Under Fire fueron películas de serie B, desprovistas de ideología política y caracterizadas por la imparcialidad. Blockade, en cambio, se concreta como la única producción importante y con grandes estrellas - Madeleine Carroll y Henry Fonda- que se realizó en Hollywood en apoyo a la causa republicana (Gubern, 1986, p. 54; Porta, 2008). Ahora bien, las tres fueron interceptadas y adulteradas por la Oficina Hays y poseen el común denominador de la ambigüedad, la confusión y la no identificación ${ }^{4}$. En realidad, Hollywood no realizaría ningún film abiertamente antifascista hasta Confessions of a Nazi Spy (Anatole Litvak, 1939), de Warner Bros. (Coma, 2002, p. 36; Doherty, 2013, p. 12).

\section{OBJETIVOS Y ESTADO DE LA CUESTIÓN}

El presente artículo propone el análisis del contenido histórico y el discurso ideológico de The Last Train From Madrid. Se trata de un título menor en el conjunto de la producción clásica de Hollywood, que, sin embargo, posee gran trascendencia por ser la primera aproximación de la industria cinematográfica norteamericana a la guerra de España. Se erige, por ello, como un testimonio excepcional tanto de la visión inaugural de la producción fílmica hollywoodiense sobre la Guerra Civil española como de la primera imagen que se ofreció al público de los Estados Unidos sobre el conflicto en una cinta comercial y con argumento narrativo.

Es una producción en extremo desconocida que, dada su condición de película de bajo presupuesto, ha sido completamente pasada por alto por los analistas fílmicos, tanto en nuestro país como en el extranjero. Asimismo, tal desatención historiográfica se debe a que jamás se ha editado de forma comercial y en la actualidad continúa sin estar disponible en formato doméstico, VHS o DVD 5 .

Así se explica que los análisis sobre el largometraje sean increíblemente exiguos. De hecho, el único extenso y detallado que hemos localizado data de 1978 y consiste en un capítulo del libro The Spanish Civil War in American and European Films (Valleau, 1982). Recientemente, destacan dos aproximaciones más, si bien mucho más breves y someras, incluidas en The Star-Spangled Screen: The American World War II Film (Dick, 1996) y Hollywood and Hitler, 1933-1939 (Doherty, 2013). En lo que atañe al ámbito español, las referencias son notablemente escasas y breves y en algunos casos los autores llegan incluso a reconocer que no han visto la película.

Por todo lo expuesto, los errores impregnan los pocos textos historiográficos que se le han dedicado, y en ocasiones cuestiones tan básicas como su fecha de estreno figuran

\footnotetext{
${ }^{3}$ En esto el censor no estaba totalmente en lo cierto, ya que Twentieth Century-Fox pretendió filmar la producción pro franquista Siege of Alcazar, proyecto que tuvo que abandonar, en noviembre de 1936, ante las numerosas protestas de grupos leales a la República. Consúltese sobre este tema: "Anti-Nazi", 1936; “UFA's”, 1936.

${ }_{4}$ Aunque, a diferencia de las otras dos, Blockade sí posee un posicionamiento político a favor del gobierno democrático de España, éste sólo aparece en el discurso final que da cierre al largometraje, a partir del cual todo lo que se ha visto con anterioridad adquiere su sentido.

${ }^{5}$ El film no se estrenó en España, como tampoco lo hicieron Love Under Fire y Blockade.
} 
equivocadas incluso en fuentes tan acreditadas como AFI Catalog of Feature Films $(2016)^{6}$. A su vez, abundan los juicios heredados, tales como que el largometraje es del todo ajeno a la realidad de la Guerra Civil española (Valleau, 1982, p. 19; Gubern, 1986, p. 58), que en él la contienda actúa meramente como telón de fondo (Valleau, 1982, p. 19; Smith, 1996, p. 34; Black, 1998, p. 315; Pastor Petit, 1998, p. 200; Coma, 2002, p. 94; Crusells, 2004, p. 166; García López, 2013, p. 181) o que es favorable a la insurrección militar de Franco (Borde, 1977, p. 70; Gubern, 1986, p. 59; Doherty, 2013, pp. 143-144).

Nuestro estudio demostrará la inexactitud de estas y otras apreciaciones. Al respecto de las dos primeras, es cierto que el largometraje desvirtúa considerablemente la Guerra Civil española, pero, al mismo tiempo, contiene también evocaciones directas a buen número de hechos históricos reales. Más importante aún, presenta una estrecha conexión con la realidad a través de la intertextualidad fílmica, puesto que Paramount infiltró en la cinta imágenes reales de un noticiario cinematográfico soviético de los bombardeos de la aviación nazi sobre Madrid. La presencia de este noticiario ruso ha permanecido desconocida hasta el momento, se identifica por primera vez en el presente trabajo y desmiente, de entrada, las aserciones de que el film ideológicamente se inclina hacia los rebeldes. Dicho lo cual, nuestra investigación persigue específicamente los siguientes objetivos:

1. Situar al film en su contexto histórico dentro de la producción de Hollywood y las actitudes de la autocensura de la MPPDA acerca de la realización de cintas sobre la Guerra Civil española.

2. Documentar históricamente la película y subsanar los errores que constan en los textos bibliográficos precedentes.

3. Identificar el origen y la procedencia de las imágenes reales de noticiarios que aparecen en el film.

4. Clarificar las dosis de realismo del largometraje.

5. Analizar su contenido histórico, a fin de diferenciar los hechos distorsionados de los que poseen una correspondencia fiel con la realidad histórica de la Guerra Civil española.

6. Constatar la neutralidad de su discurso político.

7. Determinar su mensaje ideológico global.

\section{METODOLOGÍA}

Para lograr los objetivos señalados, hemos empleado un método de análisis histórico, donde The Last Train From Madrid es estudiado a la luz de diversas fuentes cinematográficas y relacionadas con la guerra de España en dos bloques claramente diferenciados.

El primer bloque documenta el proceso de preproducción del film y su gestación dentro del contexto histórico de Hollywood, con especial atención al ejercicio y las presiones de la autocensura de la Oficina Hays y la PCA respecto de su realización y

\footnotetext{
6 AFI Catalog of Feature Films (2016). The American Film Institute Catalog Database 1893-1970. Disponible en: http://www.afi.com/members/catalog/. Consultado el 21/03/2016. A partir de aquí citado como AFI Catalog.
} 
posterior exhibición comercial. Para conocer tales restricciones y prohibiciones, se han examinado abundantes materiales documentales, sobre todo fuentes primarias de la época procedentes de publicaciones cinematográficas especializadas, tales como Film Daily, Motion Picture Daily, Motion Picture Herald, The Hollywood Reporter y Variety. El segundo bloque consiste en un análisis histórico de los pasajes narrativos más relevantes del film con objeto de establecer su conexión con los hechos reales acaecidos durante la Guerra Civil española, para lo cual se ha procedido a la confrontación de las imágenes de la cinta con textos historiográficos fílmicos y con fuentes de tipo histórico relativas a la contienda. Por último, pasamos a exponer las conclusiones de nuestro estudio.

\section{DISCUSIÓN}

\subsection{Proyecto y preproducción}

The Last Train From Madrid y Love Under Fire corrieron paralelos y comenzaron a gestarse en el otoño de 19367. De acuerdo con AFI Catalog, varios de los grandes estudios de Hollywood compitieron por la historia original de The Last Train From Madrid, del matrimonio Paul Hervey Fox y Elsie Fox, y Paramount la adquirió en noviembre de 1936 (Dick, 1996, p. 15). A fines del mismo mes, Variety informaba de que, como ocurriera con Siege of Alcazar, organizaciones antifascistas y antibelicistas estaban en contra de la producción:

Con respecto a la película de Paramount "Train", existe la sensación de que el tratamiento otorgado será estrictamente desde el ángulo del melodrama, sin decantarse por un bando o por otro. Incluso aunque Paramount estuviera inclinada a producir una película con mensaje, los grupos anti[fascistas] sienten que la productora sería disuadida por causa del incidente de Fox (“Anti-Fascist”, 1936, p. 3).

El último juicio expresado no podía ser más acertado. Si hubo algún intento de infundir posicionamiento político, fue en vano. En esta primera época de adquisición del material, la PCA ya se había concentrado en el proyecto con objeto de eliminar de él cualquier indicio de contenido ideológico (Doherty, 2013, p. 143). Además, la experiencia de Fox con Siege of Alcazar sirvió a la MPPDA como magnífico exponente de que ante todo debían evitarse posturas partidistas. De este modo, tal y como sospecharon las organizaciones antifascistas, The Last Train From Madrid iba camino de convertirse en un simple melodrama despojado de cualquier tipo de convicción.

A la vista de la película finalizada, no cabe duda de que la PCA siguió el mismo procedimiento en The Last Train From Madrid que más tarde aplicó a Love Under Fire y a Blockade (Smith, 1996, p. 23; Coma, 2002, p. 94): el término "guerra civil" no podía mencionarse; los uniformes tenían que ser inventados, diferentes de los auténticos que usaban ambas facciones enfrentadas; las alusiones a leales y rebeldes también estaban prohibidas; no podía indicarse que los insurrectos recibían ayuda extranjera, etc. Estas imposiciones formaban parte del proceso de imparcialidad y no identificación de la PCA, que implicó, a su vez, la aparición en la cinta de la ciudad

${ }^{7}$ En realidad, Love Under Fire fue el reemplazo de Twentieth Century-Fox a Siege of Alcazar. 
ficticia de Cardozo ${ }^{8}$. Así pues, la frase “¿Quién es quién? ¿Qué es lo que? ¿Y por qué razón?", escrita por un crítico contemporáneo con relación a Blockade (Smith, 1996, p. 27), se hace extensible al film que nos ocupa.

El 10 de marzo de 1937 se anunciaba que la película sería dirigida por Al Santell (“2 Spanish Pix", 1937). Pero el día 31 la productora cambiaba de opinión y la asignaba a James Hogan, de quien Variety decía que ascendía así de categoría dentro del estudio ("James P. Hogan", 1937). Nada más lejos de la realidad. The Last Train From Madrid había quedado constituida ya como una producción de serie B. Para Coma (2002, p. 93), es precisamente el cambio de director lo que evidencia el descenso de confianza de Paramount en el film y su consiguiente degradación a los bajos presupuestos, con toda probabilidad debido a las restricciones de Joseph I. Breen desde la PCA.

Por otro lado, su condición de película de serie B debe ser debidamente aclarada en el presente, máxime habida cuenta de su extraordinario reparto, compuesto por Dorothy Lamour, Lew Ayres, Gilbert Roland, Karen Morley, Lionel Atwill, Robert Cummings y Anthony Quinn. No obstante, este magnífico elenco de estrellas no era tal cosa en 1937. En realidad, The Last Train From Madrid estuvo protagonizada por un conjunto de astros en declive -Ayres, Roland, Morley y Atwill- y actores emergentes del estudio - Lamour, Cummings y Quinn 9 . Motion Picture Herald, por ejemplo, manifestó: "Aunque el reparto no proporciona grandes estrellas, incluye a actores muy conocidos, muchos jóvenes a los que Paramount está dando la oportunidad de convertirse en las estrellas del mañana" ("Last Train”, 1937a, p. 44). Variety, por su parte, la calificó de "débil en cuanto al reparto" (Kauf, 1937, p. 12)10.

Tanto por la reunión de tales intérpretes populares en un mismo largometraje como por su estructura narrativa, la crítica la definiría después como una especie de Grand Hotel (Gran Hotel, Edmund Goulding, 1932), aunque de bajo presupuesto ("Last Train", 1937b; Kauf, 1937). En efecto, como la producción de Metro-Goldwyn-Mayer, The Last Train From Madrid es una película coral, con el protagonismo compartido entre nueve personajes. Con su acción establecida en menos de 24 horas en el Madrid asediado por los nacionales, todos los implicados (algunos de forma bastante incongruente, como comprobaremos) desean tomar el último tren que sale hacia Valencia, la capital provisional de la República. Los hechos se sitúan, pues, el 6 de noviembre de 1936, con el inicio de la Batalla de Madrid y la partida del gobierno hacia esa ciudad. Para Variety, este eje articulador tomado de Grand Hotel no actuaba en beneficio de la cinta y contribuía, en cambio, a su historia confusa:

Su principal dificultad es la media docena de intrigas que posee, dentro de límites estrechos; una mezcla de "Gran Hotel" y "Shanghai Express". Y todo está confeccionado de forma tan evidente como para molestar a la audiencia. Por desgracia, porque la película en sí misma no es tan mala. Sin esa premisa y título prometedores sería más fácil aceptar esta película como un buen estreno de un programa doble (Kauf, 1937, p. 12).

\footnotetext{
8 Blockade también ostentó las localidades imaginarias italianizadas de Castelmare, que algunos han identificado con Castellón, y Montefiore, y el protagonista el nombre de Marco, en lugar de Marcos.

${ }_{9}^{9}$ Dorothy Lamour y Anthony Quinn habían debutado en la pantalla el año anterior, mientras que Robert Cummings lo hizo en 1935 con pequeñas apariciones.

10 Juicios idénticos pueden encontrarse por doquier en otros artículos coetáneos: "The Last Train", 1937b; “Last Train”, 1937c.
} 
La fecha fijada para el rodaje -15 de marzo de 1937 - se postergó debido a que la Oficina Hays, tras casi medio año de negociaciones, todavía no había dado su aprobación al guión. Por ello, AFI Catalog se equivoca cuando menciona esta fecha como arranque de la producción, que probablemente tomó de un artículo de Variety ("2 Spanish Pix", 1937)11. El veredicto favorable de los censores llegó al fin el 6 abril. Al día siguiente, Variety se hacía eco del consentimiento y apuntaba que "El estudio tuvo que eliminar varias situaciones consideradas objetables por Hays" ("Hays Finally", 1937, p. 4). A mediados de mes, Motion Picture Herald señalaba que "Tuvieron que hacerse muchos ajustes de contenido temático antes de que recibiera la aprobación de la Production Code Administration" ("Finish 7", 1937, p. 55).

Según Doherty (2013, pp. 143-144), Breen rubricó dos pasajes en el libreto para su eliminación. En el primero, los pies de un soldado leal pisoteaban un crucifijo; en el segundo, soldados republicanos llevaban a cabo una ejecución masiva de prisioneros rebeldes. Sin embargo, esta última secuencia se mantuvo, razón que motiva nuestras dudas acerca de que el autor haya visto la película, junto con otros errores en que incurre en su texto. Con relación al crucifijo, por un lado, resulta del todo lógico que el católico exacerbado Breen se negara a permitir tal afrenta a la religión en una película norteamericana; por otro, era una clara referencia a los actos de violencia contra la Iglesia Católica, asesinatos de sus miembros y destrucción de sus edificios, que se produjeron en la España republicana en los días y meses inmediatos al golpe de estado del 17 y 18 de julio de 1936, acontecimientos que conmocionaron a la opinión pública internacional y motivaron que sus artífices incluyeran la escena en el guión.

La filmación comenzó justo después del beneplácito de Breen, entre el 7 y 9 de abril ("Production Holds", 1937; "Advance Production", 1937) y se prolongó hasta los últimos días de mayo ("Finish 9", 1937). El 31 de mayo Breen escribía a Hays y le comunicaba su satisfacción con el largometraje concluido, al tiempo que subrayaba que el estudio se había esmerado por evitar tomar partido (Doherty, 2013, p. 144). Tanto fue así que la productora, por presiones inequívocas de la PCA, insertó el siguiente alegato de neutralidad oficial en el pressbook de la película, destinado al exhibidor:

Durante la producción de The Last Train from Madrid, Paramount puso mucho empeño en evitar la toma de partido por cualquiera de los bandos de este país desgarrado por la guerra, de modo que sería una buena política a seguir, evitando así cualquier posible ofensa a los espectadores. The Last Train from Madrid es estrictamente neutral en las cuestiones que se relacionan con el actual conflicto español. Si ustedes llevan a cabo una campaña en español, asegúrense de que la copia es simple y directa y "no toma partido en el actual conflicto del país" (Valleau, 1982, pp. 12-13).

Como enseguida veremos, tal posicionamiento se plasmó también en la propia cinta. A la postre, la Legión Nacional Católica de la Decencia terminó autorizando The Last Train From Madrid, aunque le concedió la categoría Class A-2 de "Aceptable para

\footnotetext{
${ }^{11}$ Como resultado, numerosos textos publicados la incluyen de forma errónea también.
} 
adultos" ("Legion Approves", 1937; "National Decency", 1937). Frente a lo afirmado por AFI Catalog, que sitúa erróneamente su fecha de estreno el 25 de junio de 1937, la película se inauguró en el Criterion Theatre de Nueva York el 18 de junio ("The Broadway”, 1937; “Motion Picture”, 1937; “1st Runs”, 1937, p. 8; Kauf, 1937).

\subsection{Análisis histórico del largometraje}

Tras los títulos de crédito, el film se inicia con un cañón lanzando una bomba. Después, surgen por sobreimpresión tres textos que inciden en la neutralidad del largometraje y fueron impuestos por Breen (Doherty, 2013, p. 144):

De la guerra han surgido los dramas más grandes del mundo -dramas que desafían a la imaginación porque su base es real.

Ésta es una historia de este tipo - una representación de personajes de ficción atrapados en el Madrid asediado, con un único deseo común - - Escapar.

Ni defendemos ni condenamos ninguna de las facciones del conflicto español. Ésta es una historia de personas - no de causas.

Los escritos figuran sobre imágenes reales de una ciudad española devastada por la guerra, con numerosos edificios en ruinas y llenos de escombros. Aunque dichas imágenes pasan por ser Madrid, Paramount en el pressbook registró que pertenecían a Palencia, adonde envió una unidad de producción para filmar la guerra civil (Valleau, 1982, p. 11). Esta impactante apertura, que alude a los desastres de la guerra e incluye material documental genuino de la contienda, otorga a The Last Train From Madrid unas expectativas de autenticidad que con frecuencia se verán defraudadas. Debe entenderse, ante todo, a modo de reclamo publicitario, al igual que los anuncios y textos promocionales distribuidos por el estudio que lo asociaban a la máxima actualidad del momento: “iLa primera película de la Guerra Civil española!" ("The Last Train", 1937a, pp. 18-19) o "The Last Train From Madrid" - la última palabra en cine tomado 'de los periódicos"” (“That's Out!", 1937, p. 3).

Después arranca el argumento propiamente dicho, con un locutor de radio emitiendo un comunicado:

Un anuncio de vital importancia. Se informa de que el último tren desde Madrid saldrá esta noche a las doce en punto. Por razones gubernamentales las comunicaciones ferroviarias de Madrid con Valencia y la costa se destruirán, se destruirán inmediatamente después de la salida de este último tren. La oficina municipal de defensa expedirá los pases especiales. Pero aquí hay una alarma ciudadana. Estos pases especiales se concederán sólo a personas acreditadas que tengan negocios importantes fuera de Madrid y a algunos militares, no a otros. Las solicitudes deben realizarse en el cuartel general provisional del capitán Ricardo Álvarez, escolta militar de este tren, en el Hotel Nacional.

Excepto en lo relativo a la sensación de pánico y desorden que existió en Madrid el 6 de noviembre de 1936 con la decisión repentina del gobierno de trasladarse a Valencia (una huida en toda regla, que demostraba que el ejecutivo estaba convencido de que Madrid estaba a punto de caer), el resto del mensaje es pura 
ficción. De hecho, en esos momentos ni siquiera existía una línea de comunicación ferroviaria directa Madrid-Valencia, algo que The Last Train From Madrid ignora por completo ${ }^{12}$.

Asimismo, conviene destacar que el desconocimiento de los artífices del film sobre la idiosincrasia de la Guerra Civil española les lleva a situar como pasajeros privilegiados del tren a personas con importantes negocios fuera de Madrid, cuando buena parte de las industrias y medios de producción de la zona republicana pasaron a manos de los trabajadores, y los empresarios en ningún caso disfrutaron de privilegios en la España republicana, más bien todo lo contrario. Éste es un error histórico en el que se insiste justo a continuación, en el Hotel Nacional, donde cientos de personas desesperadas hacen lo posible por obtener pases para el convoy y se incluye a un patrono exigiendo con vehemencia a las autoridades que protejan su fábrica.

El gobernador militar de Madrid, el coronel Vigo (Lionel Atwill), y el capitán Ricardo Alvarez (Anthony Quinn) tratan la situación altamente crítica de la República respecto de la enconada batalla que se está librando en Cardozo. Valleau (1982, p. 13) yerra por completo al identificar esta localidad ficticia con Ávila, asimilación que realiza al considerar que la ciudad estaba siendo sometida al ataque nacional en ese momento. Ávila, empero, como la mayoría de ciudades extremadamente conservadoras de Castilla y León, se rindió a los insurrectos casi sin luchar, el 19 de julio. A juzgar por la acción de la película, Cardozo no puede ser otra cosa que el mismo frente de Madrid. Por lo demás, el film sigue fielmente la historia con relación al asedio al que estaba siendo sometida Madrid en esas fechas. El 15 de octubre las tropas golpistas se habían situado en sus inmediaciones. El 4 de noviembre cayó Getafe y al día siguiente Alcorcón y Leganés. El día 6 los sublevados estaban a las puertas de la capital. La Batalla de Madrid no terminaría hasta el 23 del mismo mes ${ }^{13}$. Dado que se necesitan refuerzos, se ha ofrecido a los reclusos de las cárceles intervenir en la contienda. Surge el interrogante de si permitir también a los presos políticos contribuir al esfuerzo bélico. “¿Por qué no?", opina Ricardo, "Su único crimen es no estar de acuerdo con nosotros". Compartimos el juicio de Valleau (1982, p. 16) cuando señala que, con su comentario, él se revela como políticamente ingenuo. Ahora bien, la sola posibilidad planteada por el largometraje de que los reos políticos participen en la defensa de Madrid es tan increíble como absurda, un auténtico desatino histórico. Además, en la realidad sucedió todo lo contrario. En los días 7 y 8 de noviembre de 1936 se produjeron las sacas masivas de presos políticos en las que los republicanos fusilaron a fascistas, quintacolumnistas y derechistas en

\footnotetext{
12 La línea de ferrocarril Madrid-Valencia se hallaba en plena fase de construcción cuando comenzó la guerra, a través del tramo Cuenca-Utiel (que no se concluyó hasta 1947). Con la partida del gobierno a Valencia, la Republica consideró de máxima prioridad estratégica mantener las comunicaciones de la nueva capital con el frente de Madrid, sobre todo a partir de la Batalla del Jarama, en febrero de 1937, en que las fuerzas sublevadas pretendieron cortar las comunicaciones entre ambas ciudades. Para ello, se construyó a gran celeridad una vía alternativa que se denominó "Vía Negrín" o "Tren de los 100 días"; su primera designación hace alusión al ministro y más tarde presidente de la República Juan Negrín, que la impulsó, y la segunda al tiempo que tardó en construirse. Se terminó en junio de 1938. ${ }^{13}$ La República logró conservar Madrid, pero la ciudad se convirtió en un frente abierto durante prácticamente toda la guerra civil, hasta su caída el 28 de marzo de 1939.
} 
los pueblos cercanos a Madrid de Paracuellos del Jarama y Torrejón de Ardoz. Las ejecuciones estuvieron motivadas por las declaraciones del general Mola desde el bando nacional, quien en una entrevista radiofónica había manifestado que tenía cuatro columnas preparadas para entrar en Madrid, pero que el ataque lo iniciaría una "quinta columna", que ya estaba dentro (Preston, 2013, pp. 399-400). Se refería a los adeptos a la insurrección que habitaban en la ciudad y, sobre todo, a los prisioneros políticos que atestaban sus cárceles, en total casi ocho mil. El 7 de noviembre, con las fuerzas rebeldes a punto de entrar en Madrid, cundió el pánico entre los republicanos ante la posibilidad de que los miembros del ejército nacional y partidarios del levantamiento militar de las penitenciarias organizaran la ofensiva, por lo que se decidió evacuarlos a cárceles alejadas del frente. Sin embargo, durante el recorrido alrededor de mil doscientos fueron asesinados.

Con todo, la primera cuestión es del todo cierta: tanto en Madrid como en numerosas ciudades republicanas se proporcionó a los convictos comunes la libertad si se unían a la CNT y se atenían a luchar con la República; otras veces las milicias simplemente entraban en las cárceles y liberaban a los delincuentes corrientes, a los que consideraban víctimas de la sociedad burguesa (Preston, 2006, p. 136; Preston, 2013, 309, 347, 357, 372, 387-388, 398). Que en la misma secuencia figure este suceso tan próximo a la realidad y, a su vez, el despropósito de invitar a los presos políticos a defender Madrid nos induce a pensar que esta última acotación pudo ser sugerida por Breen en su afán de dotar de la máxima neutralidad al largometraje.

Al fin, Vigo resuelve que sólo los prisioneros comunes podrán sumarse a la batalla y entrega a Ricardo un listado con los voluntarios. Éste lo inspecciona y queda conmocionado al descubrir un nombre: Eduardo de Soto. La cámara enfoca su antebrazo con una cicatriz en forma de cruz $y$, seguidamente, un fundido encadenado da paso a otro personaje realizando la misma acción en la cárcel, que posee la misma cicatriz en el brazo: Eduardo (Gilbert Roland). Sabemos así que son hermanos de sangre. Este último explica a otros reclusos que la cicatriz se relaciona con los "Violent Five", un grupo de cinco que luchó en la Guerra colonial de Marruecos o Guerra del Rif (1909-27), del que ahora sólo quedan dos, y dice que algún día les contará la historia de Damón y Pitias. El film conecta así a Ricardo y Eduardo con la amistad más profunda y leal que existe, ya que a ese tema se refiere el relato clásico, supuestamente acaecido en el siglo IV a. C. en Siracusa, Sicilia. Poco después, Ricardo se las ingenia para liberar a Eduardo, librándole del frente de Cardozo y quebrantando su lealtad a la República. Para estos dos personajes, nada es realmente importante, ni la política, ni la ideología, ni siquiera la muerte (tampoco el amor, como se verá); nada, excepto su amistad. Además, como en la historia clásica, el personaje cuya vida estaba en peligro, Eduardo/Pitias, pasa a estar en libertad, y el que se hallaba a salvo, Ricardo/Damón, ve su vida amenazada por salvar la de su amigo.

Horas después, Eduardo visita a su antigua novia de clase alta, Carmelita Castillo (Dorothy Lamour). Tras dos años de cautiverio, ella se emociona al verle. No obstante, le informa de que abandona Madrid esa misma noche con el último tren. Aunque él quiere marcharse con ella, no puede ser: hay otro hombre. Se establece así el primer triángulo amoroso del argumento, con melodramáticas complicaciones 
añadidas, ya que el acompañante y actual prometido de Carmelita no es otro que Ricardo. Eduardo se retirará galantemente para no entrometerse entre ellos.

Por otra parte, conviene indicar que es altamente improbable que Eduardo sea un delincuente común, por sus modales, posición económica e impecable vestir. Sin embargo, de acuerdo con la decisión finalmente adoptada de que sólo los prisioneros comunes participarán en la defensa de Madrid, debemos asumir que lo es. Ahora bien, como sugiere Valleau (1982, p. 15), habría tenido mucho más sentido que fuese un preso político, especialmente al considerar su pasado durante la Guerra del Rif, ya que en ella comenzó Franco su meteórica carrera militar, y desde el norte de África y con el Ejército de Marruecos puso en marcha - el 18 de julio de 1936 - la sublevación que dio lugar a la Guerra Civil Española. En consecuencia, casi sin excepción los que intervinieron en la Guerra del Rif engrosaron las filas y/o fueron favorables a los insurrectos. Exactamente lo mismo es susceptible de ser aplicado a Ricardo, del que no se explica por qué es capitán de la República. No obstante, volviendo a Eduardo, el personaje no puede ser un reo político por diversas razones, que denotan la deficiente construcción del guión de esta subtrama. De un lado, si lo fuera, no habría podido salir de la cárcel junto con los demás presos comunes; de otro, resulta necesaria su reclusión de dos años en prisión (desde 1934, antes de la guerra civil) para justificar que Carmelita, sola y sin esperanzas de volver a verle, se haya entregado a otro hombre. Conforme a las consignas de la PCA, ella es inscrita como una señorita acaudalada, distinguida y de moral recta - por ello, Dick (1996, p. 16) sugiere que podría ser fascista - , marcando una diferenciación clara con respecto a otros tipos de mujer que aparecerán en el argumento. Así, sin esa ausencia prolongada de dos años, reforzada por otros sufrimientos, como la muerte de su padre, no se explicaría su nuevo compromiso. Con todo, y aunque el largometraje implica necesariamente que Eduardo no es un preso político, así se le anunció en la publicidad de la película suministrada por la productora ("Paramount's", 1937). De ahí, también, el error de numerosos textos historiográficos que lo citan como tal, por lo que suponemos que se documentan de tales anuncios o sinopsis (Borde, 1977, p. 70; Doherty, 2013, p. 144).

Otra línea argumental concierne a la miliciana Maria Ronda (Olympe Bradna) y al periodista norteamericano Bill Dexter (Lew Ayres). Es una de las más fidedignas a la guerra en España, dado que comienza con un grupo de milicianas en las inmediaciones de Madrid dirigiéndose hacia el frente. La miliciana es la imagen emblemática de la mujer española durante la guerra civil luchando de forma voluntaria contra el fascismo, que se difundió a nivel mundial a través de la fotografía y la prensa internacional. The Last Train From Madrid no duda en incorporarla y demuestra con ello un conocimiento mayor del conflicto del que $a$ priori se le podría presuponer. Además, la adhesión a la realidad histórica es completa, pues, de acuerdo con Thomas (1962, p. 267), una unidad exclusivamente femenina participó activamente en la defensa de Madrid en el Puente de Segovia.

La milicia es atacada por un bombardeo aéreo y sus integrantes corren para ponerse a cubierto. Maria aprovecha la oportunidad para desertar y detiene al coche de Bill. Ella le suplica que la lleve a Madrid para ver a su padre, un preso político al que van a fusilar ese mismo día. ¿Pero por qué iba Maria a necesitar la influencia de Bill si ella misma es republicana? Más incongruente aún es que luche a favor de la República y 
su progenitor pertenezca al bando nacional. Según Dick (1996, p. 16), en la historia original Maria no tenía convicciones políticas y únicamente se enrolaba en la milicia para no pasar hambre. No obstante, este dato no figura en la película y, por tanto, su afiliación y la de su padre se imponen como incompatibles y contradictorias.

Tras una breve visita al padre de María en la cárcel, ambos salen del recinto al tiempo que se produce la ejecución del Sr. Ronda y otros presos nacionales. Aunque resulta arriesgado conectar la escena con los ya aludidos fusilamientos de prisioneros políticos nacionales acaecidos el 7 y 8 de noviembre de 1936 en Paracuellos del Jarama y Torrejón de Ardoz, ya que en su día se hizo todo lo posible por silenciarlos (Preston, 2013, p. 493), su emplazamiento en el film se explica porque los ecos de ejecuciones masivas de presos por parte de los republicanos tuvieron una gran repercusión en las democracias occidentales debido a la presencia de cuantiosos periodistas extranjeros en el área leal. En cambio, las atrocidades y matanzas sistemáticas de las tropas rebeldes apenas se conocían porque junto a los insurrectos no se hallaban corresponsales de guerra que pudiesen testimoniarlas (Preston, 2013, pp. 401-402).

En el pelotón de fusilamiento un soldado rehusó apretar el gatillo: Juan Ramos (Robert Cummings). "Si la película fuese realista", expone Valleau (1982, p. 15), "le habrían matado de un disparo en ese mismo momento". No obstante, su superior tan solo le amonesta y le lleva ante el coronel Vigo. En efecto, la total ausencia de credibilidad en cuanto al proceder del ejército y sus altos mandos militares es otro particular de The Last Train From Madrid. Vigo, de hecho, meramente le reprocha su cobardía con cierta benevolencia y le impone un castigo: será transferido a Cardozo. Pero, de forma igualmente inverosímil, le concede dos horas libres y le da dinero para que las disfrute.

Mientras Juan camina entre las ruinas de Madrid, una prostituta, Lola (Helen Mack), se despide de su último cliente. De pronto y sin ninguna razón, un francotirador acaba con la vida del individuo. La escena es fiel reflejo del Madrid asediado de 1936 donde, conforme se acercaban más y más las tropas rebeldes, falangistas y conspiradores salían al anochecer y disparaban de forma aleatoria desde tejados, ventanas y azoteas (Preston, 2006, p. 190; Preston, 2013, pp. 400, 472). The Last Train From Madrid ofrece así una imagen terrorífica de Madrid, como un lugar inhabitable, en el que abundan la peligrosidad y los crímenes arbitrarios, todo lo cual se corresponde con la realidad histórica de la ciudad durante la Batalla de Madrid. Otro aspecto destacable de la producción por su fidelidad, que se intensifica en este fragmento, es el ruido constante del fuego de la artillería y las bombas. En esto, The Last Train From Madrid es por completo veraz, puesto que el estruendo de los ataques nacionales se escuchaba en la capital desde mediados de octubre (Thomas, 1962, p. 253; Preston, 2006, p. 174).

Juan ayuda a Lola a introducir al hombre en su vivienda. Enseguida comprueban que ha muerto. Pero éste tenía un pase para el último tren y Juan planea utilizarlo y desertar a Valencia. Aunque al principio Lola no quiere dárselo y le llama cobarde, cuando descubre que son del mismo pueblo, cercano a Burgos, accede a entregárselo. Ambos terminarán enamorándose y proyectarán escapar juntos a Valencia. Juan es descrito como un sensible pacifista. No obstante, como sugiere Dick (1996, p. 16), su falta de inclinación a luchar por la República puede estar relacionada con sus raíces 
en Burgos, capital del bando nacional y área muy reaccionaria y favorable a los rebeldes.

Si con anterioridad se ha mostrado un fusilamiento perpetrado por los republicanos, el film lo equilibra ahora con un bombardeo sobre la población civil de Madrid consumado por aviones alemanes al servicio de los nacionales. De este modo, la declarada neutralidad de la cinta se patentiza como efectiva.

La conexión con la realidad alcanza sus cotas más altas en este pasaje debido a que éstas son las aludidas imágenes soviéticas de la Guerra Civil española que Paramount, sorprendentemente y a pesar de la censura de la PCA, logró insertar en el largometraje. Son varios los textos que han señalado la inclusión de imágenes reales de un noticiario cinematográfico en The Last Train From Madrid sin indicar nada a propósito de su procedencia (Valleau, 1982, p. 15; Gubern, 1986, p. 58; Coma, 2002, p. 92), así como otros que erróneamente las han atribuido a material filmado por el estudio para sus noticiarios (Pastor Petit, 1998, p. 201; Doherty, 2013, p. 145). Ahora bien, como avanzábamos, no ha sido hasta la presente investigación que han podido identificarse. Pertenecen al noticiario soviético K Sobitiyam v Ispanii (Sobre los sucesos de España), de la productora Soiuzkinochronica, filmado por los operadores Roman Karmen y Boris Makasséiev, y concretamente se corresponden con la edición $\mathrm{n}^{\mathrm{o}} 10$, rodada en noviembre de 1936 en Madrid, es decir, en el momento exacto que representa el largometraje ${ }^{14}$. Sin duda, la presencia de este metraje, donde se ve a mujeres, niños y ancianos corriendo por las calles hacia los refugios, intentando huir del bombardeo aéreo de los nazis, fueron las motivaron que The Last Train From Madrid permaneciese prohibido durante el régimen franquista (Pastor Petit, 1998, p. 200), lo que al mismo tiempo refuta la teoría de que la película se inclina hacia los rebeldes.

Los restantes protagonistas del relato son la sofisticada baronesa Helene Rafitto (Karen Morley) y su amante gigoló Michael Balk (Lee Bowman), ambos extranjeros. Con ellos se establece el segundo triángulo amoroso del film, que incluye a Eduardo, siendo esta línea argumental la única que guarda relación con alguna otra anterior.

Eduardo y Helene se encuentran en un club nocturno, ella le propone que se marchen juntos en el último tren y le asegura que le conseguirá un pase. Ante la mirada vigilante de la policía republicana, él adopta la falsa identidad de Jose Vallejo, algo bastante innecesario si asumimos que no es un preso político y que, por tanto, no se le busca. Nos oponemos a la tesis de Valleau (1982, pp. 18-19) cuando vincula el registro que las autoridades efectúan en la presente escena con una crítica al bando republicano. A nuestro modo de ver, con los nacionales tan próximos y la ciudad atestada de espías y conspiradores, la inspección del local forma parte de la coyuntura normal de la defensa de Madrid. Blockade, sin ir más lejos, film de clara inclinación republicana, posee una secuencia similar. La diferencia es que aquí el espectador se identifica con Eduardo y desea que escape, algo que consigue.

14 Esta investigación está en deuda con el Dr. Rafael Rodríguez Tranche, dado que gracias a su conferencia, presentada en el Congreso internacional "Imágenes de una guerra. Carteles, fotografía y cine en España, 1936-1939", Madrid, del 26 al 28 de octubre de 2015, pudimos establecer la conexión de las imágenes con The Last Train From Madrid. Para una mayor información sobre las mismas, véase: Rodríguez Tranche, 2007, p. 67; Rodríguez Tranche, 2012, pp. 121-124. Consúltese también: SánchezBiosca, 2007, pp. 77-78; García López, 2010, pp. 35-37; García López, 2013, pp. 60, 79-80. 
Cuando Vigo conoce la actuación de Ricardo, otra vez de manera inverosímil, simplemente le arresta. Le pregunta quién es Eduardo De Soto y se confirma así que este último es un reo común, ya que Vigo no le conoce. Ricardo responde que es un amigo y expone el argumento que para Coma $(2002$, p. 94) resume ideológicamente el largometraje; esta subtrama sin duda: "Para mí hay algo más grande que el patriotismo - la amistad".

Otro falseamiento histórico grave del film lo constituye la expulsión posterior de Bill de Madrid por las autoridades, cuando es de sobra conocido que los republicanos, al contrario de lo que sucedía en el bando nacional, acogieron de buen grado a todo tipo de corresponsales, escritores, fotógrafos y periodistas extranjeros, especialmente porque la República quería dar a conocer al mundo lo que sucedía en España para lograr el apoyo y la intervención internacional.

El clímax de The Last Train From Madrid se produce en la estación de ferrocarril con los personajes intentando subir al convoy. Dado que impera el melodrama, que requiere complicaciones y que no todos consigan su objetivo, algunos mueren, otros son detenidos y sólo los "buenos" logran huir hacia Valencia. La intriga y el suspense se incrementan notablemente en la secuencia final, dado que Vigo detiene indefinidamente la salida del tren por causa de que Ricardo y Eduardo viajan en él. Helene es detenida por la policía por el asesinato de Michael, al que disparó para conseguir el pase de Eduardo. Mientras que Juan y Lola, de camino a la estación, son atacados por unos saboteadores y ella muere. Conforme a las normas morales de la PCA, es absolutamente compresible que Lola y Helene vean frustrados sus planes; la primera, por su condición de mujer perdida; y la segunda, porque es una femme fatal y culpable de asesinato. También muere Ricardo, quien, de forma completamente heroica, romántica e irreal, entrega su vida para que su mejor amigo y su novia puedan marcharse juntos a Valencia. Carmelita y Eduardo, Maria y Bill y también Juan se van en el convoy.

\section{CONCLUSIONES-RESULTADOS}

La confusión, la ambigüedad y el desorden son las notas predominantes de The Last Train From Madrid. A lo largo de este trabajo, hemos aludido a la República española y a la existencia de dos bandos enfrentados, ya que de no ser así nuestro análisis habría resultado ininteligible. No obstante, ha de tenerse en cuenta que tales especificidades no constan en la cinta, entre otras razones porque se concibió con una voluntad de imparcialidad y no identificación antepuesta desde el inicio. El film tan solo permite distinguir que hay una guerra en curso en España, pero ni siquiera se sabe qué o quién la ha originado, por qué se combate o cuáles son las facciones en conflicto. Todo debe ser deducido, interpretado y descifrado por el espectador.

Nuestro examen ha demostrado que en The Last Train From Madrid se dan cita tanto elementos insostenibles y que se alejan considerablemente de la realidad histórica de la Guerra Civil española como otros que son del todo ciertos y se atienen a hechos verídicos. Con referencia a estos últimos, a modo de síntesis podríamos concretar:

1. El reclutamiento de presos comunes para contribuir a la defensa de la República.

2. La presencia de las milicianas participando en la Batalla de Madrid. 
3. El fusilamiento masivo de prisioneros políticos por parte de los republicanos, que podría aludir a las ejecuciones de los días 7 y 8 de noviembre de 1936 en Paracuellos del Jarama y Torrejón de Ardoz.

4. Los bombardeos aéreos de la aviación nazi sobre la población civil de Madrid, plasmados de forma fidedigna mediante la inserción intertextual de un fragmento de un noticiario cinematográfico soviético.

5. La peligrosidad e inseguridad ciudadana del Madrid de noviembre de 1936, con abundantes francotiradores y saboteadores armados.

6. El acusado realismo en la descripción de Madrid como una ciudad sitiada, especialmente desde el punto de vista sonoro, por el incesante estruendo de las bombas y el fuego de la artillería.

Todas estas cuestiones vinculadas con la beligerancia contradicen los textos previos que han manifestado que el film carece de conexión con la guerra de España. Sin embargo, advertimos que el número de acontecimientos falseados e incoherentes es mucho mayor, pues cabría subrayar:

1. Se dispone como pasajeros prioritarios del tren a los empresarios y se incluye a uno reclamando a las autoridades republicanas que salvaguarden su fábrica, sucesos más que improbables en la España gobernada por el Frente Popular.

2. Desde el punto de vista histórico, la disyuntiva de que los prisioneros fascistas intervengan en la defensa de Madrid se adentra en el terreno de lo disparatado.

3. Dado el pasado de Eduardo en la Guerra del Rif, lo congruente habría sido que fuera un preso político. Pero, por deficiencias de guión, se le inscribe como un vulgar delincuente.

4. La misma trayectoria militar de Ricardo lo adscribiría, por lógica, a la guarnición nacional. Empero, es capitán de la República y no se proporcionan explicaciones al respecto.

5. Que Maria integre las filas de la milicia republicana y su padre pertenezca al bando golpista es otra circunstancia incongruente, que se acentúa aún más porque él está sentenciado a muerte por los republicanos.

6. Maria no tendría por qué necesitar ayuda para ver a su progenitor antes de morir y, como mínimo, debería tener mayor influencia que un extranjero.

7. La expulsión de Bill, periodista norteamericano, de la zona republicana se distancia por completo de la realidad histórica de la Guerra Civil española.

8. El importante y último tren que sale de Madrid a Valencia (línea de ferrocarril que no existía en la España de 1936) está a punto de cancelarse por razón de dos individuos insignificantes que no han cometido traición política alguna: Ricardo, que liberó a un convicto corriente, y Eduardo, el reo en cuestión.

9. Las conductas del ejército se perciben como inverosímiles por ser enormemente benévolas y sentimentales en plena guerra.

10. De forma en extremo injustificada, todos los personajes desean conseguir pases para el convoy y marcharse a Valencia, porque ésa es la fuerza motriz sobre la que se construye el argumento conforme al género del melodrama. 
No obstante, muchos son desertores y/o perseguidos por los republicanos Ricardo, Eduardo, Maria y Juan - y, por tanto, debieran querer permanecer en Madrid, dado que la ciudad está a punto de caer bajo el poder franquista.

Tal vasto número de acontecimientos desvirtuados e imposibles responde a una combinación de factores, entre los que cabe contemplar: el ejercicio de la PCA; la ausencia de un conocimiento profundo de la naturaleza y la singularidad de la Guerra Civil española; y el énfasis por adscribirse a las convenciones genéricas del melodrama e introducir elementos de emoción, aventura y suspense en una ciudad sitiada. En consecuencia, The Last Train From Madrid deja de lado la lógica y se convierte en una película ininteligible desde una perspectiva histórica.

En cuando a su ideología, es deliberadamente neutral. La Oficina Hays le impuso tal posicionamiento y en líneas generales consiguió mantenerse imparcial, tal y como creemos que ha quedado demostrado en el análisis por cómo el largometraje compensa los actos censurables de un bando y de otro. Por ello, es inútil intentar extraer de él algún tipo de inclinación política o ideológica. Con todo, deben considerarse algunas implicaciones involuntarias de la cinta.

La principal es que, al emplazar la acción en el Madrid cercado por los nacionales, representa la Guerra Civil española desde el lado republicano y plasma una imagen trágica de Madrid como una ciudad asfixiante, claustrofóbica y dominada por el terror, debido al acecho del invasor. Asimismo, las imágenes reales que aparecen en el film - las iniciales de Madrid en ruinas (en verdad, Palencia) y las del bombardeo aéreo - poseen gran impacto emocional y son el resultado de ese peligro exterior desconocido. Por último, y más importante, el hecho de que a los nacionales jamás se les vea - tan solo bombardeando - los convierte en una presencia más aterradora y amenazadora todavía, inscribiéndoles como el enemigo. Hasta tal punto es así que Valencia, zona republicana, se equipara con la libertad, el lugar al que todos desean escapar para alejarse del horror que se avecina, incluso aunque algunos de los personajes tienen sobradas razones para no continuar en la zona leal, ya que están siendo buscados por las autoridades. Pero, aun así, prefieren huir.

Aunque estos últimos elementos supondrían una inclinación favorable hacia el bando republicano, ésta se desdibuja al reparar en que ni uno solo de los protagonistas siente lealtad o deseo de luchar por la República. De tal modo que la ambigüedad se impone de nuevo.

En suma, la relevancia de The Last Train From Madrid reside en ser la primera representación de la industria cinematográfica de Hollywood sobre la Guerra Civil española en un film de ficción con completa escenificación en España, realizado, además, de forma simultánea a su actividad. Actúa, en consecuencia, como documento histórico y claro reflejo de las posturas oficiales de neutralidad y no injerencia que compartían tanto la Oficina Hays como el gobierno estadounidense. Y, en este sentido, vaticina lo que terminaría ocurriendo en la historia: la no intervención de las potencias democráticas occidentales en la guerra de España. 


\section{REFERENCIAS}

Advance Production Chart (14 de abril de 1937). Variety, 126(5), 24.

AFI Catalog of Feature Films (2016). The American Film Institute Catalog Database 18931970. Disponible en: http://www.afi.com/members/catalog/

Anti-Fascist and Anti-War Bodies In U.S. Keen on Supporting 2 New Pix (25 de noviembre de 1936). Variety, 124(11), 3.

Anti-Nazi Raps Vs. Smith Shorts, 20th's "Alcazar" (4 de noviembre de 1936). Variety, 124(8), 7, 25.

Black, G. D. (1998). Hollywood Censurado. Madrid: Cambridge University Press.

Borde, R. (enero, 1977). “La guerre d'Espagne vue par Hollywood. Sus trois films commerciaux". Les Cahiers de la Cinémathèque, 21, 68-71.

Dick, B. F. (1996). The Star-Spangled Screen: The American World War II Film. Lexington, KY: The University Press of Kentucky.

Coma, J. (2002). La Brigada Hollywood. Guerra española y cine americano. Barcelona: Flor del Viento Ediciones.

Crusells, M. (diciembre, 2004). Cinema as a Political Propaganda during the Spanish Civil War: España 1936. Ebre 38, 2, 157-168.

Doherty, T. (2013). Hollywood and Hitler, 1933-1939. New York, NY: Columbia University Press.

Finish 7; Start 8 (17 de abril de 1937). Motion Picture Herald, 127(3), 55.

Finish 9; Start 8 (29 de mayo de 1937). Motion Picture Herald, 127(9), 39.

García López, S. (2010). Imágenes del cielo. Tres calas en el cine extranjero de la Guerra Civil. Secuencias, 31, 32-48.

García López, S. (2013). Spain is Us. La Guerra Civil española en el cine del Popular Front: 1936-1939. Valencia: Universitat de València.

Gubern, R. (1986). 1936-1939: La guerra de España en la pantalla. De la propaganda a la Historia. Madrid: Filmoteca Española.

Hays Finally Ok's Par's “Madrid" (7 de abril de 1937). Variety, 126(4), 4.

James P. Hogan Boosted To Top Par Meg List (31 marzo de 1937). Variety, 126(3), 6. 
Kauf (23 de junio de 1937). Last Train from Madrid. Variety, 127(2), 12.

Last Train for [sic] Madrid (22 de mayo de 1937a). Motion Picture Herald, 127(8), 44.

“Last Train” Keen Melo (5 de junio de 1937b). The Hollywood Reporter, 3.

Last Train from Madrid (12 de junio de 1937c). Motion Picture Herald, 127(11), 80.

Legion Approves All Of 11 New Pictures (14 de junio de 1937). Motion Picture Daily, 41(138), 12.

Motion Picture Daily's Hollywood Preview (17 de junio de 1937). Motion Picture Daily, 41(141), 4.

National Decency Legion Classifies 11 New Pictures (19 de junio de 1937). Motion Picture Herald, 127(12), 52.

Paramount's “The Last Train from Madrid” (7 de junio de 1937). Film Daily, 71(132), 4.

Pastor Petit, D. (1998). Hollywood responde a la Guerra Civil (1936-1939). Barcelona, España: Ediciones de la Tempestad.

Porta, O. (Productor y director) (2008). Hollywood contra Franco. [Película documental]. España: Área de Televisión, en asociación con Televisió de Catalunya y la participación de TVE, ICAA e ICIC.

Preston, P. (2006). La Guerra Civil española. Barcelona: Debate.

Preston, P. (2013). El holocausto español. Odio y exterminio en la Guerra Civil y después. Barcelona, España: Debolsillo.

Production Holds; 41 Features Going (10 de abril de 1937). Motion Picture Daily, $41(84), 1$.

Rodríguez Tranche, R. (2007). Escenas de Madrid bajo las bomba. En V. SánchezBiosca (Ed.). España en armas. El cine de la guerra civil española (pp. 63-70). Valencia: Museu Valencià de la Il.lustració i de la Modernitat (MuVIM).

Rodríguez Tranche, R. (2012). Miedo y terror en el Madrid republicano. De los bombardeos a la quinta columna. En N. Berthier \& V. Sánchez-Biosca (Eds.). Retóricas del miedo. Imágenes de la Guerra Civil Española (pp. 115-126) Madrid: Casa de Velázquez. 
Sánchez-Biosca, V. (2007). Propaganda y mitografía en el cine de la guerra civil española (1936-1939). Cuadernos de información y Comunicación, 12, 75-94.

Smith, G. M. (1996). Blocking Blockade: Partisan Protest, Popular Debate, and Encapsulated Texts. Cinema Journal, 36(1), 18-38.

That's Out! (24 de mayo de 1937). Film Daily, 71(121), 3.

The Broadway Parade (14 de junio de 1937). Film Daily, 71(138), 2.

The Last Train From Madrid (14 de mayo de 1937a). Motion Picture Daily, 41(113), 1819.

The Last Train from Madrid (8 de junio de 1937b). Motion Picture Daily, 41(133), 8.

Thomas, H. (1962). La guerra civil española. París: Editions Ruedo Ibérico.

UFA's "Alkazar" but 20th-Fox Heeds Beefs (18 de noviembre de 1936). Variety, 124(10), 3.

Valleau, M. A. (1982). The Spanish Civil War in American and European Films. Ann Arbor, MI: University of Michigan Press.

1st Runs on Broadway (23 de junio de 1937). Variety, 127(2), 8.

2 Spanish Pix - 20th and Par's Scripts Against Revolution Background (10 de marzo de 1937). Variety, 125(13), 2.

\section{AUTOR}

\section{Carmen Guiralt Gomar:}

Es Doctora en Historia del Arte por la Universidad de Valencia, con una tesis en la rama de Historia del Cine sobre el director norteamericano Clarence Brown, Licenciada en Historia del Arte por la misma universidad y Máster en Historia y Estética de la Cinematografía por la Universidad de Valladolid. Sus principales líneas de divulgación científica se centran en la historia y la estética del cine clásico norteamericano. Ha publicado numerosos artículos de investigación en revistas científicas altamente reconocidas en el ámbito de su especialidad e intervenido con comunicaciones en diversos congresos científicos internacionales. Entre sus contribuciones a obras colectivas destaca el libro Ciudades de Cine (Editorial Cátedra, 2014), donde ha participado con el capítulo dedicado a Washington, D.C. Actualmente, acaba de concluir un monográfico sobre el director Clarence Brown para la Editorial Cátedra, que será el primer libro publicado sobre el cineasta a nivel mundial y verá la luz en la colección de la editorial "Signo e Imagen/Cineastas" a comienzos de 2017. https://www.researchgate.net/profile/Carmen_Guiralt_Gomar 
Guiralt Gomar, C. La primera aproximación de Hollywood a la Guerra Civil Española: the last train from Madrid (1937)

https://independent.academia.edu/CarmenGuiraltGomar http://orcid.org/0000-0003-1409-6675 